\title{
Erratum to: The Effect of the Pinning Center Size on the Vortex Pinning by Embedded $\mathrm{ZrO}_{2}$ Nano-particles
}

\author{
Nahed Moutalbi · Asma Ouerghi · Ali M'chirgui
}

Published online: 31 January 2012

(C) Springer Science+Business Media, LLC 2012

Erratum to: J. Supercond Nov Magn (2011) 24:165-168 DOI 10.1007/s10948-010-0912-8

A slightly distorted version of Fig. 3 was inadvertently printed. Here is the correct Fig. 3.

Although our comments in the text are unaffected, the authors regret this carelessness.

The online version of the original article can be found under doi:10.1007/s10948-010-0912-8.

N. Moutalbi · A. Ouerghi · A. M'chirgui $(\varangle)$

Department of Physics, Faculty of Sciences, 7021 Zarzouna,

Bizerte, Tunisia

e-mail: ali.mchirgui@fsb.rnu.tn

\section{A. M'chirgui}

Systems and Applied Mechanics Laboratory (LASMAP),

Polytechnic School of Tunisia, Rue El Khawarezmi, B.P. 743,

La Marsa, Tunis, Tunisia

e-mail: ali_mc_fsb@yahoo.fr
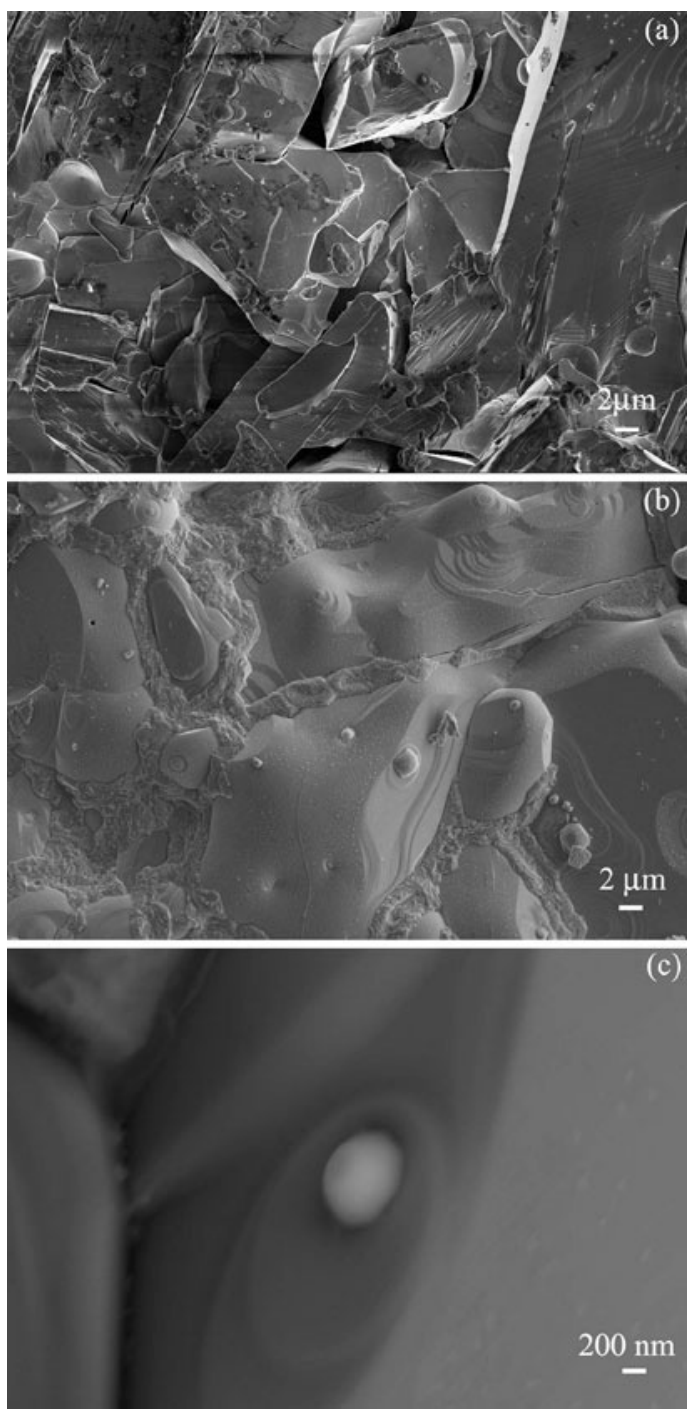

Fig. 3 Microstructure images from the bulk of (a) pure YBCO, (b) and (c) $D_{1} \mathrm{ZrO}_{2}$ doped $\mathrm{YBCO}$ 